\title{
Transmission Electron Microscopy at Atmospheric Pressure
}

Xiaoqing Pan ${ }^{1,2}$ Shuyi Zhang ${ }^{1,3}$, Sheng Dai ${ }^{1,3}$, George W. Graham ${ }^{3}$

${ }^{1}$ Department of Chemical Engineering and Materials Science, University of California - Irvine, Irvine, California, USA.

${ }^{2}$ Department of Physics and Astronomy, University of California - Irvine, Irvine, California, USA.

${ }^{3}$ Department of Materials Science and Engineering, University of Michigan, Ann Arbor, Michigan, USA.

The ability to monitor dynamic processes in-situ is crucial for understanding structure-property relationships in nano-engineered materials. In the past decade, the majority of atomic-scale electron microscopy studies involving gas-solid interactions were conducted in an environmental transmission electron microscope (ETEM), where the gas pressure is typically limited to no more than $1 / 100$ of at atmosphere. Recently, it has become possible to overcome this limitation through the use of a MEMSbased, electron-transparent closed cell with sample heating stage. In this talk, we illustrate the power of this device as applied to our study of two important catalyst systems: (1) the structural evolution of supported $\mathrm{Pd} @ \mathrm{CeO}_{2}$ and (2) the ordering and $\mathrm{Pt}$ surface enrichment in supported $\mathrm{Pt}_{3} \mathrm{Co}$. For this work, we used the Protochips Atmosphere ${ }^{\mathrm{TM}}$ system [1], in which the sample is situated between two SiN windows, each of 30-50 nm in thickness, with a 5 um gap in between, in combination with a JEOL $3100 \mathrm{R} 05$ double aberration corrected transmission electron microscope (TEM) operating at $300 \mathrm{kV}$ in scanning mode.

Core-shell structures consisting of modular palladium-ceria core-shell subunits $\left(\mathrm{Pd} @ \mathrm{CeO}_{2}\right)$, assembled in solution from discrete $2 \mathrm{~nm}$ crystallites of $\mathrm{Pd}$ and $\mathrm{CeO}_{2}$, then supported on silicon-functionalized alumina, have shown exceptional activity for methane combustion [2], attracting widespread interest from the catalysis community. In fact, we found that the sample actually consists of loosely assembled clusters of $\mathrm{Pd}$ and $\mathrm{CeO}_{2}$ nanoparticles (NPs), each $\sim 2-3 \mathrm{~nm}$ in diameter, in close proximity after air calcination at $500{ }^{\circ} \mathrm{C}$ for $5 \mathrm{~h}$. In-situ observations performed in 150 Torr of $\mathrm{O}_{2}$ subsequently revealed that an unexpected structural transformation occurs upon further heating at temperatures between 500 and $800{ }^{\circ} \mathrm{C}$. As the temperature was increased above $500{ }^{\circ} \mathrm{C}$, atoms on the corners of smaller $\mathrm{CeO}_{2} \mathrm{NPs}$ started to leave the NPs, causing them to shrink, while atom 'clouds' simultaneously began to form, as shown in Figure 1. As the temperature of the sample was increased toward $650{ }^{\circ} \mathrm{C}$, contraction of the cloud, accompanied by the growth of the surrounding $\mathrm{CeO}_{2} \mathrm{NPs}$ was observed. Eventually, the system reached a stable state, where large $\mathrm{CeO}_{2} \mathrm{NPs}, \sim 5-10 \mathrm{~nm}$ in diameter, together with very small entities, $\sim 1-2 \mathrm{~nm}$ across, are both present in the sample. It seems that the newly formed structure, comprised of an intimate mixture of palladium, cerium, silicon, and oxygen with extremely high dispersion, is more likely to account for the exceptional catalytic properties that have been reported.

Another core-shell structured NP, having a thin Pt shell and a non-noble metal core (Fe, Co, $\mathrm{Ni}$, etc.), is a promising oxygen reduction reaction (ORR) catalyst in polymer electrolyte membrane fuel cells. To better understand the formation process of the Pt shell, which is crucial for enhancing ORR activity, we investigated carbon-supported $\mathrm{Pt}_{3} \mathrm{Co}$ catalysts by in-situ electron microscopy, combined with first principle calculations. The disordered alloy was found to transform to an ordered intermetallic after high temperature $\left(750{ }^{\circ} \mathrm{C}\right)$ annealing in 760 Torr of $\mathrm{O}_{2}$, followed by layer-by-layer Pt shell growth on (100) surfaces at low temperature $\left(300^{\circ} \mathrm{C}\right)$, as shown in Figure 2. The apparent "anti-oxidation" phenomenon 
promoted by the ordered $\mathrm{Pt}_{3} \mathrm{Co}$ phase is favorable to the ORR catalyst, which functions in an oxidizing environment. [3]

References:

[1] Allard, L.F. et al., Microsc. Microanal. 18 (2012), 656.

[2] Cargnello, M. et al., Science 337 (2012), 713.

[3] The authors gratefully acknowledge funding from the National Science Foundation under grants DMR-0723032 and CBET-115940.
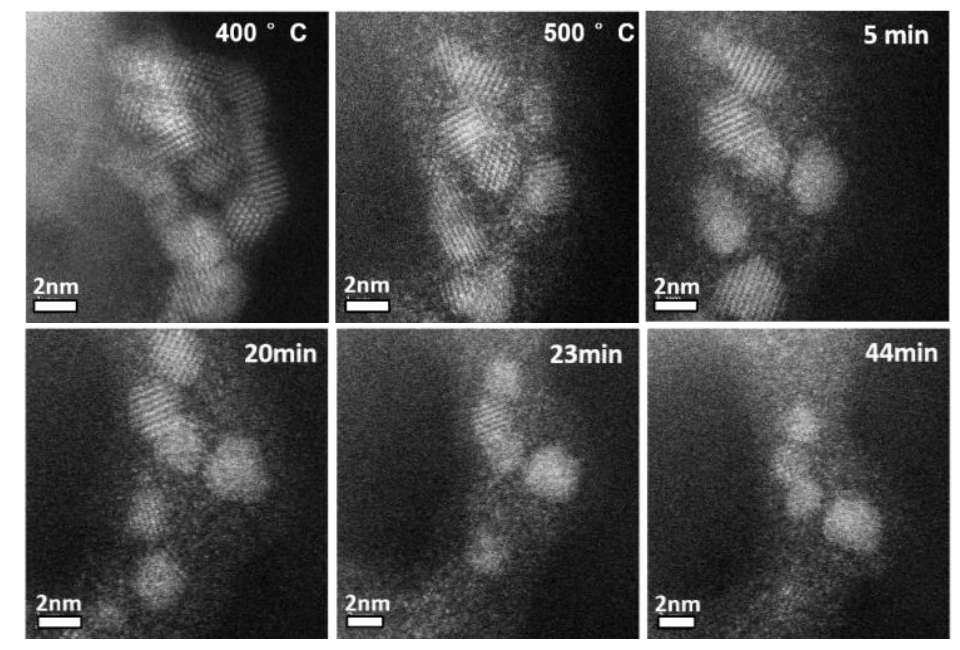

Figure 1 Sequential Scanning Transmission Electron Microscopy (STEM) images showing the dissociation of 2-3 nm CeO 2 NPs and the formation of atom 'clouds' during in-situ heating at just above $500{ }^{\circ} \mathrm{C}$ in 150 Torr $\mathrm{O}_{2}$.

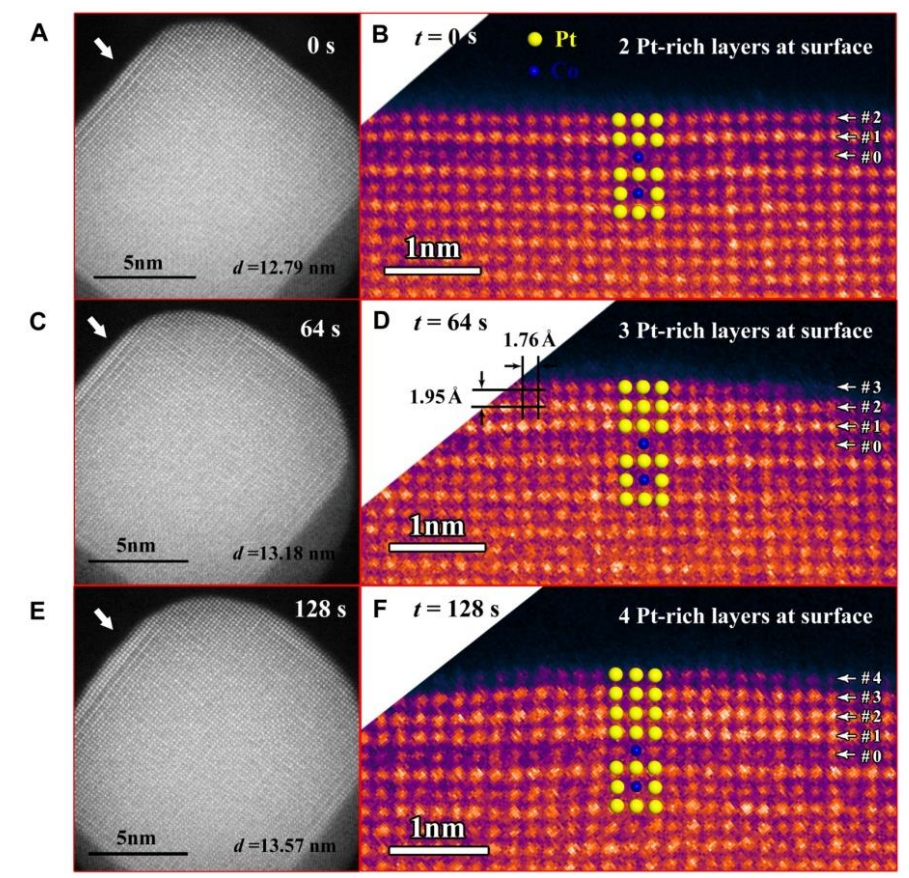

Figure 2 Sequential in-situ STEM images (taken inside the gas cell under $\mathrm{O}_{2}$ at atmospheric pressure, at temperatures in the range of $700-750{ }^{\circ} \mathrm{C}$ ) showing an oxygen-driven core-shell formation process in ordered $\mathrm{Pt}_{3} \mathrm{Co}$ NPs. 